\title{
Haemodialysis in the Octogenarian: More Than a Decade of Experience from a Single UK Centre
}

\author{
Philip Thomas, Anna Price, and Jyoti Baharani \\ Department of Nephrology, Birmingham Heartlands Hospital, Bordesley Green East, Birmingham, West Midlands B9 5SS, UK \\ Correspondence should be addressed to Philip Thomas; philip.thomas1@nhs.net
}

Received 27 August 2015; Accepted 8 December 2015

Academic Editor: Motoo Kikuchi

Copyright (C) 2016 Philip Thomas et al. This is an open access article distributed under the Creative Commons Attribution License, which permits unrestricted use, distribution, and reproduction in any medium, provided the original work is properly cited.

\begin{abstract}
Background. To assess factors affecting survival in an octogenarian cohort commencing haemodialysis (HD) and describe outcomes associated with prolonged survival. Materials and Methods. We retrospectively analysed 11 years of data (1 January 2000-31 December 2010) from patients aged $\geq 80$ years starting HD at a teaching hospital in the United Kingdom. Data was collected on patient demographics, aetiology of renal failure, indication and duration of $\mathrm{HD}$, access type at first dialysis, Charlson comorbidity index score, and cause of death. Results. Data from 139 eligible patients was included for analysis ( 85 male, 54 female (1.54:1)). The mean age was $83.6 \pm 2.8$ years and $90 \%$ of this cohort were Caucasian. Thirty percent $(42 / 139)$ of the cohort died within 90 days of starting dialysis. For those who survived $>90$ days the mean (median) duration of HD was 871.8 (805) days. Long-term survival was more common in females and those who first dialysed through an AVF. Conclusions. There is a significant early mortality risk in octogenarians commencing HD. For individuals who survive beyond the initial 90 days, the majority have a good long-term survival and our results are better than previously published UK data. Long-term survival was more common in female patients and those starting HD using an AVF.
\end{abstract}

\section{Introduction}

Historically renal replacement therapy (RRT) was only considered a feasible treatment option in younger patients with little comorbidity [1, 2]. In 1984 a survey revealed that half of nephrologists would not offer dialysis to a 50 -year-old with ischaemic heart disease [3]. Two decades later, Oreopoulous et al. warned that 21 st century nephrologists will be mainly practicing geriatric medicine and nephrologists needed to prepare for this "coming of age" [4]. True to that statement, today HD is considered a viable treatment option for all ages including the very elderly as a result of positive advances in medicine [2].

The ageing global population will exert pressures on all aspects of health and social care over the coming years [5]. Chronic kidney disease (CKD) is now primarily a disease of older adults and the number of individuals requiring RRT is likely to increase $[4,6]$. In the UK, patients aged over 65 represent the fastest growing group of the dialysis population with their numbers increasing by a third between 2005 and 2008 [3].
The decision to start dialysis in the very elderly remains difficult and their subsequent management brings its own unique set of challenges [7]. The burden of comorbidity and polypharmacy is more prevalent in older adults' further complicating outcomes [8]. Older people are likely to require dialysis for the rest of their lives and are unlikely to undergo transplantation $[9,10]$. Clinicians are therefore obliged to identify those older adults at risk of a poor outcome and attempt to strike a balance between offering treatment which will prolong life and overmedicalisation of what should be a natural death $[8,11]$.

Commencing dialysis is a life changing event but even more so for older people who may have impaired cognitive function or are functionally dependent on others for basic care $[8,12]$. Any increase in frailty whilst on dialysis has wider effects on their primary carers and society $[8,12]$.

We must also consider that once the decision has been made and dialysis has commenced outcomes are not always favourable [8]. There is a higher risk of accidental falls, accelerated decline, and risk of early death $[8,12]$. 
RRT however is not without its merits. Treatment can prolong life as shown by Joly et al. who compared octogenarians receiving dialysis to those having conservative treatment and showed that median survival was longer at 28.9 months in those receiving dialysis compared to 8.9 months in the conservative group [13]. Dialysis was associated with better symptomatic relief from fluid overload and uraemia than conservative therapy [14]. In addition, for those who would otherwise not leave home, dialysis creates a support network of professionals and other renal patients [14].

There is no evidence base to support that age alone is predictive of mortality in elders on dialysis [9]. Multiple factors including age can influence mortality including late referral and comorbidities particularly ischaemic heart disease [8]. Therefore, until more reliable prognostic factors for older patients are established, denying dialysis on age alone remains ethically unviable [9].

Previous studies on those commencing HD after 80 years of age have been cautiously optimistic $[15,16]$. Hatakeyama et al. studied 141 Japanese patients undergoing HD and found that those over 80 years had median survival time of 2.6 years [16]. This might be expected due to the social differences and a relatively high life expectancy in Japan compared to the UK [16]. In Israel, however, Zingerman et al. who studied twentynine patients aged over 80 also found that median survival was comparable at 38 months [15].

Although AVF is the gold standard for vascular access, evidence within the elderly population is lacking [17]. Watorek et al. found that AVF was attempted in as many $87.2 \%$ of their cohort over the age of 80 and primary function was achieved in over half [18]. Nadeau-Fredette et al., however, found that primary failure was more frequent in the elderly and an AVF was not associated with a reduction in mortality [17]. This emphasises the importance of careful patient selection [17].

Whilst there remains a paucity of clinical data to help guide clinical decision making, older adults are often excluded from clinical trials and large studies [8, 9]. Our work follows an octogenarian cohort commencing HD at an urban UK centre in an effort to identify factors associated with prolonged survival on dialysis.

\section{Materials and Methods}

Our centre is situated in East Birmingham and provides renal care to an ethnically and socioeconomically diverse group of patients living in the West Midlands. Our service consists of a main dialysis hub located at the hospital with four satellite units. Referrals to nephrology come from a variety of sources including primary care, other hospital departments, and dialysis crash landers. The estimated catchment population is 1.8 million patients with an annual RRT acceptance rate of 137 per million population. The average age at the start of RRT is 64.5 years with a median of $66-67$ years. The predominant acceptance ethnicity is European $70-75 \%$ with $18-25 \%$ from the Indian subcontinent and the remainder being either African or Oriental in origin. There is a $1: 1$ male to female gender ratio.
For the purpose of the present study, dialysis crash landers and patients with acute kidney injury thought to be reversible were excluded from the analysis and we have focussed on those individuals starting chronic HD. The requirement for dialysis was based on clinical and biochemical parameters as decided by the clinician seeing the patient.

Predialysis care offered at our centre is of a high standard with the lowest number of crash landers in the country [19]. Patients are seen in the CKD clinic or referred directly from primary care or other medical specialities into a multidisciplinary low clearance clinic where education and preparedness for RRT and transplantation take place. The education is delivered on a one to one basis with the concept of shared decision making at the fore. If patients chose not to dialyse, then they are transferred to an established conservative management programme where all aspects of CKD care are undertaken with the exception of dialysis.

Retrospective data from patients aged 80 years or older commencing chronic HD between 1 January 2000 and 31 December 2010 were analysed. In the United Kingdom, patients commencing dialysis receive information that their data will be collected and collated by the Renal Registry and may be used for research purposes. We have not sought explicit consent to undertake this study as all patients had received/are receiving dialysis and we have assumed that their consent holds. Patients were excluded if they had been transferred to our centre having started haemodialysis elsewhere as we were unable to accurately assess their other comorbidities and could not determine what predialysis care they had received.

Data was obtained from the hospital's renal database (PROTON) and electronic patient records system (iCARE) which is prospectively updated. Demographic data was collected (age, ethnicity, and sex) and Charlson comorbidity index scores were calculated and unadjusted for age [20]. Charlson comorbidity index scores were calculated using information from patient notes, electronic patient record, and renal database (PROTON). Aetiology of end stage renal disease, access at first haemodialysis session, and whether patients were known to the nephrology service for greater than three months prior to starting dialysis were recorded. The location of death was collated, but cause of death could not be established in all patients due to death in the community or at different centres.

Statistical tests were carried out using IBM SPSS statistics version 19. Age was analysed using an unpaired $t$-test. The Charlson comorbidity score and albumin levels were analysed using Mann-Whitney $U$ tests. Survival was analysed using a Kaplan-Meier graph. All other factors were analysed using Fisher's exact test to account for small frequencies where possible or, alternatively, a Pearson Chi-squared test.

\section{Results}

139 patients were eligible for inclusion over an 11-year period. 85 were male and 54 female $(1.54: 1)$ with a mean age of $83.6 \pm$ 2.8 years (range $80-92$ years). Patients aged over 80 years of age accounted for $10.9 \%$ (139/1279) of new HD starters during the study period. 
TABLE 1: Summary table of each group's demographics.

\begin{tabular}{|c|c|c|c|c|}
\hline & Overall cohort $(n=139)$ & Survived $<90$ days $(n=42)$ & Survived $>90$ days $(n=97)$ & $P$ value \\
\hline Demographics & & & & 0.450 \\
\hline Mean age (median) & $83.6(83.1)$ & $83.9(83.7)$ & $83.5(82.9)$ & \\
\hline Range (min-max) & $80-92.1$ & $80-91.3$ & $80.1-92.1$ & \\
\hline Male : female & $85: 54$ & $28: 14$ & $57: 40$ & \\
\hline Ethnicity & & & & 0.552 \\
\hline Caucasian & $125(89.9 \%)$ & $39(92.9 \%)$ & $86(88.7 \%)$ & \\
\hline Non-Caucasian & $14(10.1 \%)$ & $3(7.1 \%)$ & $11(11.3 \%)$ & \\
\hline Charlson comorbidity index score & & & & 0.560 \\
\hline Low risk $\leq 3$ & 80 & 22 & 58 & \\
\hline Medium risk 4-7 & 54 & 19 & 35 & \\
\hline High risk $\geq 8$ & 5 & 1 & 4 & \\
\hline Mean & 3.45 & 3.5 & 3.4 & \\
\hline Median & 3 & 3 & 3 & \\
\hline Indication for haemodialysis & & & & 0.543 \\
\hline Biochemical & $65(46.8 \%)$ & $19(45.2 \%)$ & $46(47.4 \%)$ & \\
\hline Fluid overload & $48(34.5 \%)$ & $17(40.5 \%)$ & $31(32.0 \%)$ & \\
\hline Unknown & $26(18.7 \%)$ & $6(14.3 \%)$ & $20(20.6 \%)$ & \\
\hline Albumin at start of RRT & & & & 0.109 \\
\hline Mean (median) & $35.8(37)$ & $34.9(36)$ & $36.13(38)$ & \\
\hline Range (min-max) & $19-45$ & $19-44$ & $19-45$ & \\
\hline
\end{tabular}

At the time of data analysis, 12 patients were still alive and receiving dialysis. These individuals have been receiving dialysis for between 3 and 6 years.

A third of the cohort $(30.2 \%$; $42 / 139)$ died within 90 days of commencing dialysis. For the remainder, who survived the initial 90-day period, median survival was 805 days (range 98-2454 days). In this later group, 57.7\% (56/97) survived for more than 1 year and $22.7 \%$ (22/97) survived for more than 3 years after starting HD. Twelve patients were still alive at the time of data analysis and had been receiving RRT for between 3 and 6 years.

Baseline demographics, comorbidity index, albumin, and indication for haemodialysis are shown in Table 1 for both groups.

There was no significant difference in age between those who survived less than 90 days and those who survived over 90 days $(P=0.450)$. Ninety percent of the cohorts were Caucasian. No firm conclusions could be drawn in relation to patient's survival and ethnic origin $(P=0.552)$ due to the low numbers of ethnic minority patients in the study cohort. Overall, the comorbidity burden was relatively low with the median score being 3 in both survival cohorts. In the $<90$-day survivors, low and medium risk patients accounted for the vast majority of this group (97.6\%, 41/42 patients). This proportion was lower in the prolonged survival group at $95.9 \%(93 / 97$ patients $)(P=0.560)$. Equally, albumin at the start of dialysis was similar in both groups $(P=0.109)$.

Longer survival was more common in females with women accounting for $41.2 \%(40 / 97)$ of patients in this prolonged survival cohort compared to $33.3 \%(14 / 42)$ in the short-term survival group, but this did not reach statistical significance $(P=0.450)$. In both cohorts, the majority of patients had similar indications for starting dialysis $(P=$ $0.543)$.
TABLE 2: Influence of prior contact with the renal team on mode of first dialysis.

\begin{tabular}{lcc}
\hline $\begin{array}{l}\text { Known to renal team }>90 \text { days } \\
\text { prior to 1st RRT }\end{array}$ & $\begin{array}{c}\text { Dialysis mode } \\
\text { at 1st RRT }\end{array}$ & $\begin{array}{c}\text { Number of } \\
\text { patients }(\%)\end{array}$ \\
\hline $\begin{array}{c}\text { AVF } \\
N=72\end{array}$ & $\begin{array}{c}45(32.4 \%) \\
\text { Permcath }\end{array}$ & $11(7.9 \%)$ \\
& $\begin{array}{c}\text { Temporary } \\
\text { line }\end{array}$ & $16(11.5 \%)$ \\
\hline No & AVF & $6(4.3 \%)$ \\
$N=41$ & $\begin{array}{c}\text { Permcath } \\
\text { Temporary } \\
\text { line }\end{array}$ & $17(12.2 \%)$ \\
\hline & AVF & $18(12.9 \%)$ \\
Unknown & Permcath & $5(3.6 \%)$ \\
$N=26$ & Temporary & $11(7.9 \%)$ \\
& line & \\
\hline
\end{tabular}

A greater proportion of long-term survivors commenced HD through an AVF as seen in Figure 1, but this did not reach significance $(P=0.264)$. Over $95 \%$ of these patients commencing haemodialysis with an AVF had prior outpatient contact with the renal service. Prior contact with the renal team meant that patients were more likely to receive their first dialysis session via an arteriovenous fistula (see Table 2).

In both groups, the most common diagnosis for end stage renal failure was uncertain aetiology (small kidneys on imaging) accounting for more than $42 \%$ of cases. Obstructive 
TABLE 3: Aetiology of end stage renal disease.

\begin{tabular}{|c|c|c|c|}
\hline & Overall cohort $(n=139)$ & Survived $<90$ days $(n=42)$ & Survived $>90$ days $(n=97)$ \\
\hline Uncertain aetiology & $59(42.4 \%)$ & $18(42.9 \%)$ & $41(42.3 \%)$ \\
\hline Obstructive uropathy & $14(10.1 \%)$ & $6(14.3 \%)$ & $8(8.3 \%)$ \\
\hline Diabetic nephropathy & $11(7.9 \%)$ & $4(9.6 \%)$ & $7(7.3 \%)$ \\
\hline Renovascular disease & $19(13.7 \%)$ & $5(11.9 \%)$ & $14(14.4 \%)$ \\
\hline Multiple myeloma & $7(5.0 \%)$ & $3(7.1 \%)$ & $4(4.1 \%)$ \\
\hline Amyloidosis & $4(2.9 \%)$ & $3(7.1 \%)$ & $1(1.0 \%)$ \\
\hline Glomerulonephritis/vasculitis & $14(10.1 \%)$ & $3(7.1 \%)$ & $11(11.3 \%)$ \\
\hline Other $^{\dagger}$ & $11(7.9 \%)$ & 0 & $11(11.3 \%)$ \\
\hline
\end{tabular}

${ }^{\dagger}$ Other conditions include the following: pyelonephritis $(n=2)$; nephrectomy $(n=3)$; polycystic kidney disease $(n=2)$; interstitial nephritis $(n=2)$; acute tubular necrosis $(n=1)$; and renal hypoplasia $(n=1)$.

TABLE 4: Cause of death.

\begin{tabular}{|c|c|c|c|}
\hline Cause of death & Survived $<90$ days $(n=42)$ & Survived $>90$ days $(n=97)$ & $P$ value ${ }^{* *}$ \\
\hline $\begin{array}{l}\text { Cardiac cause (cardiac arrest, myocardial infarction, } \\
\text { and congestive cardiac failure) }\end{array}$ & $15(35.7 \%)$ & $17(17.5 \%)$ & 0.148 \\
\hline Treatment withdrawal & $8(19.1 \%)$ & $13(13.4 \%)$ & 0.799 \\
\hline Unknown & $7(16.7 \%)$ & 19 (19.6) & $\mathrm{n} / \mathrm{a}$ \\
\hline Alive & N/A & $13(13.4 \%)$ & $\mathrm{n} / \mathrm{a}$ \\
\hline Infection & $8(19.1 \%)$ & $24(24.7 \%)$ & 0.181 \\
\hline Stroke & $2(4.8 \%)$ & $4(4.1 \%)$ & 1.00 \\
\hline Gastrointestinal haemorrhage & $1(2.4 \%)$ & $1(1.0 \%)$ & 1.00 \\
\hline Malignancy & $1(2.4 \%)$ & $3(3.1 \%)$ & 1.00 \\
\hline Miscellaneous* & 0 & $3(3.1 \%)$ & 0.550 \\
\hline
\end{tabular}

${ }^{*}$ Miscellaneous category includes accidents, ischaemic bowel, and respiratory failure.

** Statistical analysis performed excluding patients with unknown cause of death and those alive.

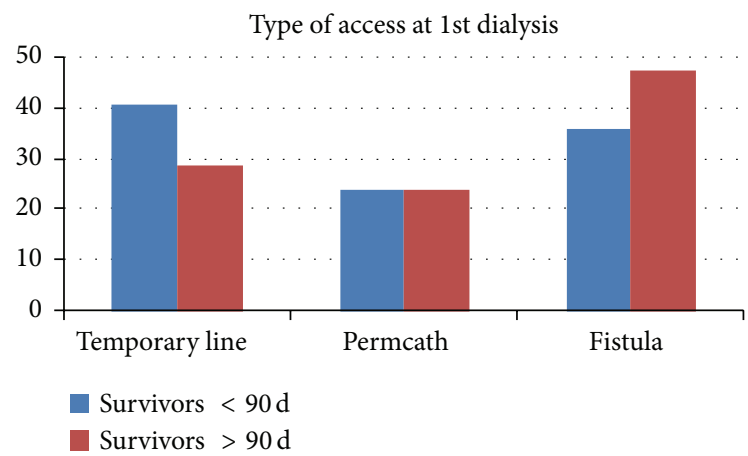

Figure 1: Type of access at first HD session.

uropathy accounted for a greater proportion of cases in the short-term survival group (14.2\%) when compared to the prolonged survivors $(8.2 \%)(P=0.336)$. Renovascular disease was more prevalent in long-term survivors $(P=$ $0.781)$. The proportions of other aetiologies such as diabetic nephropathy $(P=0.72)$, multiple myeloma $(P=0.42)$, and glomerulonephritis $(P=0.49)$ were broadly similar in both patient cohorts. Aetiology of end stage renal disease is presented in Table 3.
In the short-term survival group, cardiac causes accounted for $35.7 \%$ of deaths (see Table 4 ). Treatment withdrawal accounted for nearly a fifth of this cohort at $19.1 \%$, with infective causes accounting for the same proportion of deaths. By comparison, in the longer survival cohort, infective causes accounted for nearly a quarter of deaths at $24.7 \%(P=0.181)$. The proportion of deaths from a cardiac cause was $17.5 \%(P=0.148)$.

Of our cohort of 139 patients, it was unclear from records whether 26 patients were known to renal services prior to dialysis and therefore they were excluded. This was due to transfers from other hospitals in the area and the long followup period during which electronic data collection systems at the hospital changed. Of the remaining 113 patients, 72 (63\%) patients were receiving predialysis nephrology care at least three months prior to the start of haemodialysis. There were $41(37 \%)$ patients who had received predialysis nephrology care less than three months prior to starting HD. A comparison of survival of patients known to services greater than three months and less than three months is illustrated in Figure 2.

Although the graph illustrates an initial survival benefit of being known to the predialysis team, this benefit diminishes over time. There was no statistical difference in survival between the two groups $(P=0.766$ (log-rank)). 


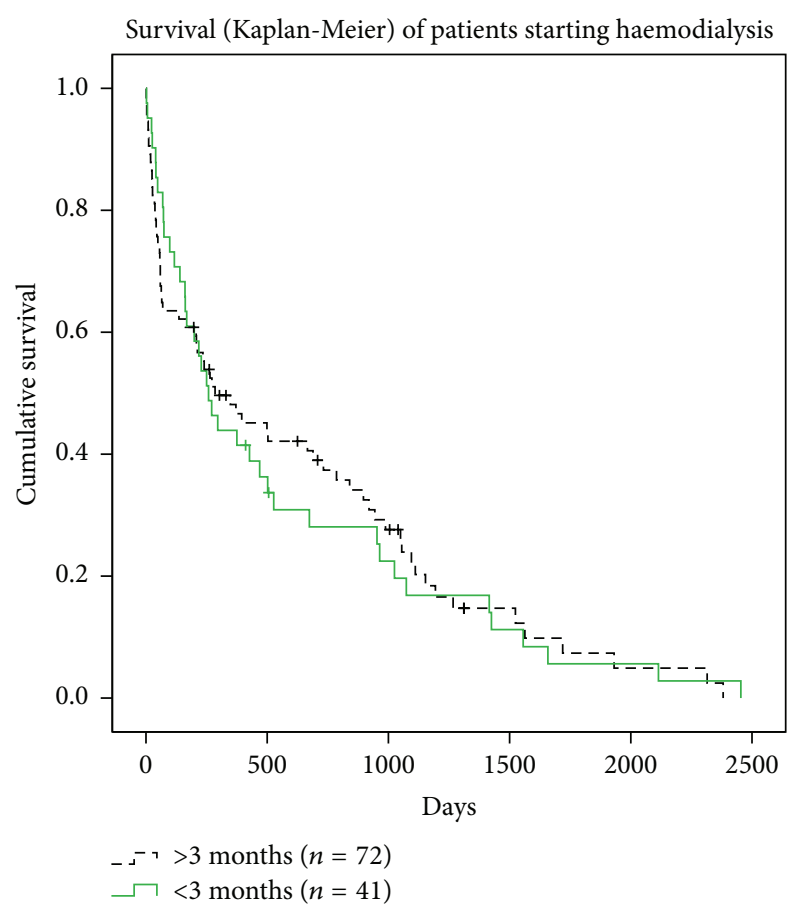

Figure 2: Survival (Kaplan-Meier) curve of 113 patients who commenced haemodialysis over 80 years of age. Dashed line: patients who received greater than 3 months of predialysis tertiary care. Solid line: patients who received less than 3 months of predialysis tertiary care.

\section{Discussion}

The world's population is ageing and the growing prevalence of CKD, especially in the older adults, presents a major challenge to the health services. This is partly due to the paradigm shift which has occurred in nephrology over the last 30 years. Medical advances have meant that RRT is now considered a real treatment option for an increasingly complex group of older patients.

The rigours of this lifesaving treatment, however, represent a significant undertaking for an elderly person and this burden is partially responsible for the high withdrawal rate from dialysis in this group [21]. We observed that $15.1 \%(21 / 139)$ of our cohort were withdrawn from dialysis therapy and this figure is in keeping with previously published results [22]. These high attrition rates have prompted some physicians to advocate for greater shared decision making $[21,23]$. This would include altering the method of dialysis delivery in order to achieve goals important to the patient and consideration of conservative management as a valid treatment modality in individuals for whom dialysis is not tolerated $[21,23,24]$.

In the United Kingdom, healthcare is free at the point of access. At our centre we have used a patient-centred approach since early 2000. When discussing management options for end stage renal failure (ESRF) we include conservative strategies alongside individually tailored RRT options. This management approach coupled with our high rate of contact with patients approaching ESRF aims to ensure that frail older patients receive the most appropriate treatment for them as individuals and these decisions are not influenced by potential financial incentives which has been suggested elsewhere in the literature [25].

There is, however, a lack of data regarding the clinical outcomes of octogenarians commencing HD as most studies refer to the elderly as being aged 65 years or older. The UK Renal Registry data estimates that the median life expectancy for a patient aged over 75 years on dialysis is approximately 3 years and is comparable to American data from United States Renal Data System where the expected remaining lifetime is 2.7 years for patients aged $80-84$ years [26, 27]. We found that the median survival in our cohort is 805 days for individuals who survive the first 90 days of dialysis therapy which is superior to previously published UK data where median survival was reported as being 328 days [28]. Our outcome is comparable to survival data from Berlin and Paris where the median survival is reported to be 26 and 28.9 months, respectively $[13,29]$. Data exists to suggest that clinical outcomes for elderly patients starting dialysis have improved in recent years. Glaudet et al. examined clinical outcomes for patients starting dialysis aged 75 years or older in France [30]. They observed that an increasing number of older adults were being established on dialysis with improved survival which were partly attributed to improved dialysis treatment and predialysis care [30].

Our results confirm that there is a significant early mortality in octogenarians commencing HD with $30 \%(42 / 139)$ of the cohort dying within 90 days of starting RRT. This result is reflective of data from the UK Renal Registry which found a $23 \% 90$-day mortality in patients aged $\geq 65$ years [27]. In the United States, incident end stage renal disease (ESRD) patients commencing haemodialysis their first year mortality from day 1 is 268.8 deaths per 1000 patient years at risk [31].

We attempted to identify factors associated with prolonged survival to assist clinicians with clinical decision making with regard to offering the octogenarians RRT. We observed trends that female gender and first dialysis through an AVF are associated with improved survival although these results did not reach statistical significance. This may be a reflection of the relatively small sample size. The observation that females survive longer is to be expected as females have a greater life expectancy compared to their age-matched male peers. Overall, Charlson comorbidity index scores were low in our cohort of octogenarians which is likely to represent selection bias. No significant differences in the median Charlson scores existed between the two survivor cohorts $(P=0.560)$.

The present study has only a modest number of patients with diabetes mellitus and this may not be reflective of the prevalence of diabetes mellitus in the octogenarian population. Our study only included those individuals commencing haemodialysis and the low prevalence of diabetes mellitus may potentially affect the results obtained as diabetes can influence management decisions such as the choice of vascular access.

No firm conclusions can be drawn about ethnicity in relation to survival in this age group on the basis of our data. This study population was skewed by the large number of 
Caucasian patients and does not reflect the ethnic diversity of the local population. We hypothesise that this is due to the burden of comorbid disease in ethnic minority populations (hypertension and diabetes mellitus) which results in these individuals reaching end stage renal disease at an earlier age compared to their peers of European ancestry. Issacs et al. found however that Caucasoid ethnicity is predictive of poor survival [32].

We have observed a trend that initial dialysis through an AVF was associated with prolonged survival. This finding has been shown in other clinical studies [30]. Our centre has a good record of commencing RRT with an AVF with our centre being the fifth highest in the UK for initial dialysis using an AVF [33]. In the United Kingdom, the use of arteriovenous grafts (AVG) is uncommon and none of the patients in this study dialysed via an AVG. Only $1 \%$ of patients dialyse via an AVG at 3 months in the United Kingdom [33]. Our centre has a well-established predialysis programme and has the lowest rate of late presenters $(<10 \%)$ amongst the centres in the United Kingdom contributing to the Renal Registry database [19]. The trend of increased survival in those individuals who initially dialyse through an AVF probably reflects improvements in predialysis care [34]. The National Service Framework for Renal Services published by the Department of Health in the UK in 2005 has resulted in a national reduction in the number of late presentations [35]. This document highlighted the significance of chronic kidney disease to non-nephrologist and the importance of early referral to specialist services [35]. The Fistula First Initiative and whether it is applicable to the octogenarian population has led to debate amongst nephrologists, but it would appear that dialysis via an AVF does improve survival in the octogenarian [36]. We are aware that selection of the appropriate mode of vascular access presents a difficult decision for physicians and a variety of factors contribute to the decision-making process such as frailty, comorbid disorders, and expected life expectancy of the patient. A recent study published by DeSilva et al. examined which vascular access was established first in predialysis patients using the US Renal Registry data [37]. They observed that only a sixth of patients had an AVF created prior to starting $\mathrm{HD}$, but this was associated with superior survival [37].

It is also known that functional status rather than an individual's age is more sensitive in predicting their likely outcome on dialysis [38]. Studies have shown that emotional quality of life measures in elderly patients on RRT is comparable to their non-dialysis peers [39]. However, octogenarians are likely to have a marked functional decline in the years after starting dialysis. Data from the United States found that the proportion of patients living independently declined from $78 \%$ before starting dialysis to $11 \%$ after 2 years of follow-up [40].

With regard to predialysis care Gubensek et al. studied a cohort of 170 octogenarian patients and found that around $60 \%$ of their patients were known to a nephrologist for greater than three months prior to dialysis [41]. Interestingly in contrast to our study they found that prior nephrology care was an independent predictor of survival [41]. The median age of patients was the same as our cohort (83 years) and there were comparable fistula rates $36 \%$ versus $32.4 \%$ [39]. There were however significantly more males in our cohort $62 \%$ versus $49 \%$ and females had better survival rates [41]. In 2015 Leimbach et al. also found markedly differing survival rates with at least three months of nephrology care with a higher rate of early referral than our cohort 79\% versus 63\% [42]. Mean age was also similar to our cohort (84 years) and there were more males 57\% compared to Gubensek et al.s study [41].

In contrast to this Issacs et al. found that duration of nephrology care prior to dialysis did not affect survival [32]. The discrepancy in survival rates based on early and late nephrology referral is likely to be based on ethnicity, comorbidities, and international differences in intensity of predialysis input [42].

\section{Conclusion}

The growing epidemic of ESRF provides a unique challenge to those managing this life-limiting illness [3]. Medical advances have brought new clinical and ethical dilemmas as an increasingly complex group of older adults are considered candidates for dialysis.

The present study has shown that median survival for octogenarian patients commencing haemodialysis is better than what has previously been reported. We observed trends that female patients and initial dialysis through an AVF were associated with prolonged survival.

Further study is needed in order to reduce the significant mortality observed in the elders commencing haemodialysis. Special care needs to be taken in this initial period and the dialysis programme may need to be tailored to the individual in combination with frequent monitoring.

Over the coming years, the very elderly will form an increasing proportion of the dialysis population and their complexity will continue to challenge the healthcare community both ethically and clinically. Further work is needed to identify prognostic factors which will assist in providing patients with clear predictions about their survival and the potential impact their choices about dialysis may have on their quality of life.

\section{Conflict of Interests}

The authors declare that they have no conflict of interests.

\section{References}

[1] S. V. Jassal and J. M. Roscoe, "Dialysis in old age-are we really doing all we should?" Age and Ageing, vol. 28, no. 5, pp. 503-504, 1999.

[2] E. Gabbay, M. Hersch, L. Shavit et al., "Dialysis by the book? Treatment of renal failure in a 101-year-old patient," Clinical Kidney Journal, vol. 6, no. 1, pp. 90-92, 2013.

[3] E. A. Brown and L. Johansson, "Dialysis options for end-stage renal disease in older people," Nephron Clinical Practice, vol. 119, supplement 1, pp. c10-c13, 2011.

[4] D. G. Oreopoulos and N. Dimkovic, "Geriatric nephrology is coming of age," Journal of the American Society of Nephrology, vol. 14, no. 4, pp. 1099-1101, 2003. 
[5] M. H. Rosner, E. Abdel-Rahman, and M. E. Williams, "Geriatric nephrology: responding to a growing challenge," Clinical Journal of the American Society of Nephrology, vol. 5, no. 5, pp. 936-942, 2010.

[6] V. Selvarajah and C. Isles, "End-stage renal disease in the very elderly," The Journal of the Royal College of Physicians of Edinburgh, vol. 37, pp. 141-146, 2007.

[7] B. Canaud, L. Tong, F. Tentori et al., "Clinical practices and outcomes in elderly hemodialysis patients: results from the Dialysis Outcomes and Practice Patterns Study (DOPPS)," Clinical Journal of the American Society of Nephrology, vol. 6, no. 7, pp. 1651-1662, 2011.

[8] I. Dasgupta and H. C. Rayner, "In good conscience-safely withholding dialysis in the elderly," Seminars in Dialysis, vol. 22, no. 5, pp. 476-479, 2009.

[9] F. Aucella, "Epidemiologic and clinical challenges of geriatric nephrology," Journal of Nephrology, vol. 23, supplement 15, pp. S1-S4, 2010.

[10] S. R. Kaufman, "Fairness and the tyranny of potential in kidney transplantation," Current Anthropology, vol. 54, supplement 7, pp. S56-S66, 2013.

[11] C. Smith, M. Da Silva-Gane, S. Chandna, P. Warwicker, R. Greenwood, and K. Farrington, "Choosing not to dialyse: evaluation of planned non-dialytic management in a cohort of patients with end-stage renal failure," Nephron Clinical practice, vol. 95, no. 2, pp. c40-c46, 2003.

[12] S. V. Jassal and D. Watson, "Dialysis in late life: benefit or burden," Clinical Journal of the American Society of Nephrology, vol. 4, no. 12, pp. 2008-2012, 2009.

[13] D. Joly, D. Anglicheau, C. Alberti et al., "Octogenarians reaching end-stage renal disease: cohort study of decision-making and clinical outcomes," Journal of the American Society of Nephrology, vol. 14, no. 4, pp. 1012-1021, 2003.

[14] F. E. M. Murtagh, J. E. Marsh, P. Donohoe, N. J. Ekbal, N. S. Sheerin, and F. E. Harris, "Dialysis or not? A comparative survival study of patients over 75 years with chronic kidney disease stage 5," Nephrology Dialysis Transplantation, vol. 22, no. 7, pp. 1955-1962, 2007.

[15] B. Zingerman, A. Korzets, Y. Ori et al., "The very old on hemodialysis: 8 years' experience in a single unit," Blood Purification, vol. 37, no. 1, pp. 12-17, 2014.

[16] S. Hatakeyama, H. Murasawa, I. Hamano et al., "Prognosis of elderly Japanese patients aged $\geq 80$ years undergoing hemodialysis," The Scientific World Journal, vol. 2013, Article ID 693514, 7 pages, 2013.

[17] A.-C. Nadeau-Fredette, R. Goupil, B. Montreuil, A. Carignan, and M. Leblanc, "Arteriovenous fistula for the 80 years and older patients on hemodialysis: is it worth it?" Hemodialysis International, vol. 17, no. 4, pp. 594-601, 2013.

[18] E. Watorek, T. Golebiowski, M. Kusztal et al., "Creation of arteriovenous fistulae for hemodialysis in octogenarians," Hemodialysis International, vol. 18, no. 1, pp. 113-117, 2014.

[19] J. Gilg, R. Pruthi, and D. Fogarty, "UK Renal Registry 17th annual report: chapter $1 \mathrm{UK}$ renal replacement therapy incidence in 2013: national and centre-specific analyses," Nephron, vol. 129, supplement 1, pp. 1-29, 2015.

[20] M. E. Charlson, P. Pompei, K. L. Ales, and C. R. MacKenzie, "A new method of classifying prognostic comorbidity in longitudinal studies: development and validation," Journal of Chronic Diseases, vol. 40, no. 5, pp. 373-383, 1987.
[21] S. Muthalagappan, L. Johansson, W. M. Kong, and E. A. Brown, "Dialysis or conservative care for frail older patients: ethics of shared decision-making," Nephrology Dialysis Transplantation, vol. 28, no. 11, pp. 2717-2722, 2013.

[22] B. Birmelé, M. François, J. Pengloan et al., "Death after withdrawal from dialysis: the most common cause of death in a French dialysis population," Nephrology Dialysis Transplantation, vol. 19, no. 3, pp. 686-691, 2004.

[23] A. M. O’Hare, N. Armistead, W. L. Funk Schrag, L. Diamond, and A. H. Moss, "Patient-centered care: an opportunity to accomplish the 'Three Aims' of the National Quality Strategy in the Medicare ESRD program," Clinical Journal of the American Society of Nephrology, vol. 9, no. 12, pp. 2189-2194, 2014.

[24] V. Grubbs, A. H. Moss, L. Cohen et al., "A palliative approach to dialysis care: a patient-centered transition to the end of life," Clinical Journal of the American Society of Nephrology, vol. 9, no. 12, pp. 2203-2209, 2014.

[25] B. Thorsteinsdottir, K. M. Swetz, and J. C. Tilburt, "Dialysis in the frail elderly-a current ethical problem, an impending ethical crisis," Journal of General Internal Medicine, vol. 28, no. 11, pp. 1511-1516, 2013.

[26] United States Renal Data System, 2014 Annual Data Report: An Overview of the Epidemiology of Kidney Disease in the United States, National Institutes of Health, National Institute of Diabetes and Digestive and Kidney Diseases, Bethesda, Md, USA, 2014.

[27] R. Steenkamp, C. Shaw, and T. Feest, "UK Renal Registry 15th annual report: chapter 5 survival and causes of death of UK adult patients on renal replacement therapy in 2011: national and centre-specific analyses," Nephron Clinical Practice, vol. 123, no. 1, pp. 93-123, 2013.

[28] F. Ronsberg, C. Isles, K. Simpson, and G. Prescott, "Renal replacement therapy in the over-80s," Age and Ageing, vol. 34, no. 2, pp. 148-152, 2005.

[29] B. Röhrich, G. Asmus, D. von Herrath, and K. Schaefer, "Is it worth performing kidney replacement therapy on patients over 80 ?" Nephrology Dialysis Transplantation, vol. 11, no. 12, pp. 2412-2413, 1996.

[30] F. Glaudet, C. Hottelart, J. Allard et al., "The clinical status and survival in elderly dialysis: example of the oldest region of France," BMC Nephrology, vol. 14, article 131, 2013.

[31] United States Renal Data System, "Mortality," in 2013 Annual Data Report, chapter 5, pp. 263-270, National Institutes of Health, National Institute of Diabetes and Digestive and Kidney Diseases, Bethesda, Md, USA, 2013.

[32] A. Isaacs, A. Burns, and A. Davenport, "Is dialysis a viable option for the older patient? outcomes for patients starting dialysis aged 80 years or older," Blood Purification, vol. 33, no. 4, pp. 257-262, 2012.

[33] V. Briggs, D. Pitcher, C. Shaw, R. Fluck, and M. Wilkie, "UK Renal Registry 16th annual report: chapter 142012 multisite dialysis access audit in England, Northern Ireland and Wales and 2011 PD one year follow-up: national and centre-specific analyses," Nephron Clinical Practice, vol. 125, no. 1-4, pp. 275294, 2013.

[34] J. Gilg, A. Rao, and D. Fogarty, "UK renal registry 16th annual report: chapter $1 \mathrm{UK}$ renal replacement therapy incidence in 2012: national and centre-specific analyses," Nephron-Clinical Practice, vol. 125, no. 1-4, pp. 1-27, 2013.

[35] The National Service Framework for Renal Services Part Two: Chronic Kidney Disease, Acute Renal Failure and End of Life Care, Department of Health, London, UK, 2005. 
[36] T. J. Vachharajani, S. Moossavi, J. R. Jordan, V. Vachharajani, B. I. Freedman, and J. M. Burkart, "Re-evaluating the fistula first initiative in octogenarians on hemodialysis," Clinical Journal of the American Society of Nephrology, vol. 6, no. 7, pp. 1663-1667, 2011.

[37] R. N. DeSilva, B. K. Patibandla, Y. Vin et al., "Fistula first is not always the best strategy for the elderly," Journal of the American Society of Nephrology, vol. 24, no. 8, pp. 1297-1304, 2013.

[38] R. J. Schmidt, "Informing our elders about dialysis: is an ageattuned approach warranted?" Clinical Journal of the American Society of Nephrology, vol. 7, no. 1, pp. 185-191, 2012.

[39] D. L. Lamping, N. Constantinovici, P. Roderick et al., "Clinical outcomes, quality of life, and costs in the North Thames dialysis study of elderly people on dialysis: a prospective cohort study," The Lancet, vol. 356, no. 9241, pp. 1543-1550, 2000.

[40] S. V. Jassal, E. Chiu, and M. Hladunewich, "Loss of independence in patients starting dialysis at 80 years of age or older," The New England Journal of Medicine, vol. 361, no. 16, pp. 16121613, 2009.

[41] J. Gubensek, R. Ponikvar, R. Ekart, and J. Buturovic-Ponikvar, "Very old patients on hemodialysis: how they start and can we predict survival?” Blood Purification, vol. 38, pp. 74-79, 2014.

[42] T. Leimbach, J. Kron, J. Czerny, B. Urbach, S. Aign, and S. Kron, "Hemodialysis in patients over 80 years," Nephron, vol. 129, no. 3, pp. 214-218, 2015. 


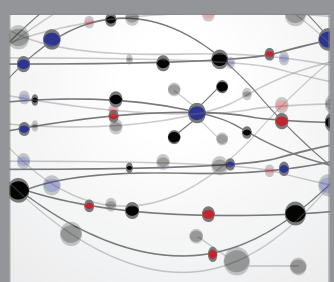

The Scientific World Journal
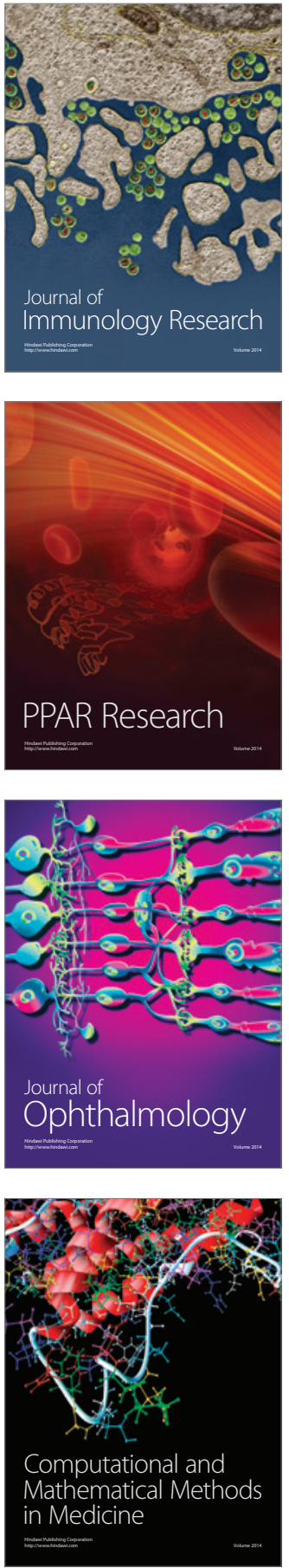

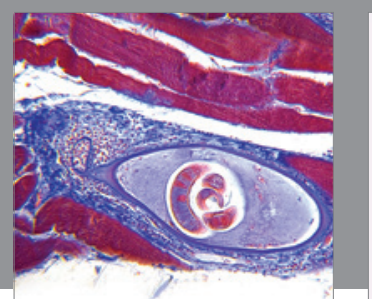

Gastroenterology Research and Practice

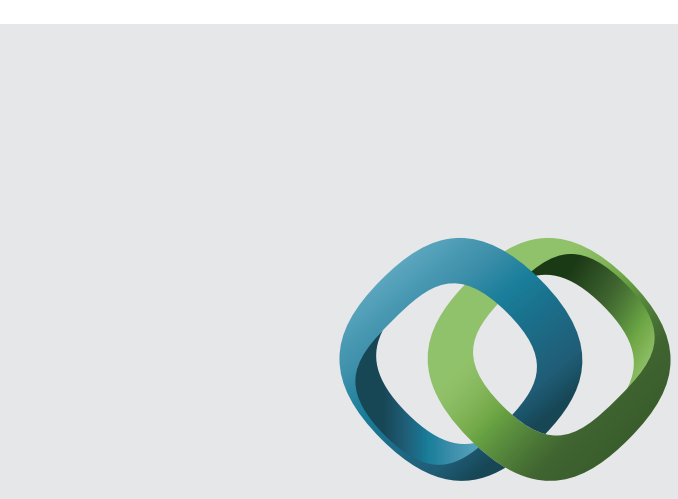

\section{Hindawi}

Submit your manuscripts at

http://www.hindawi.com
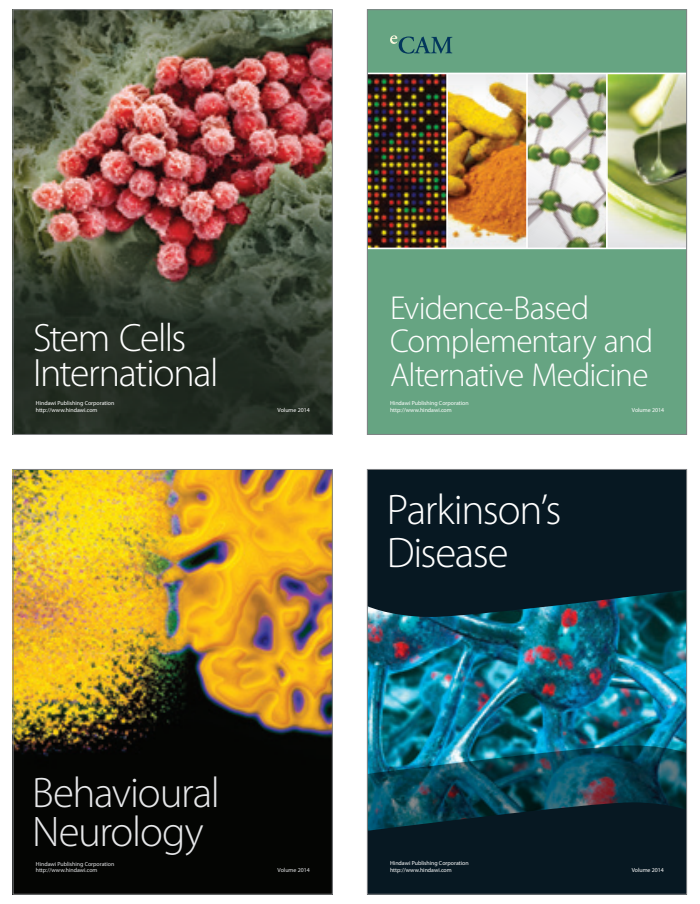
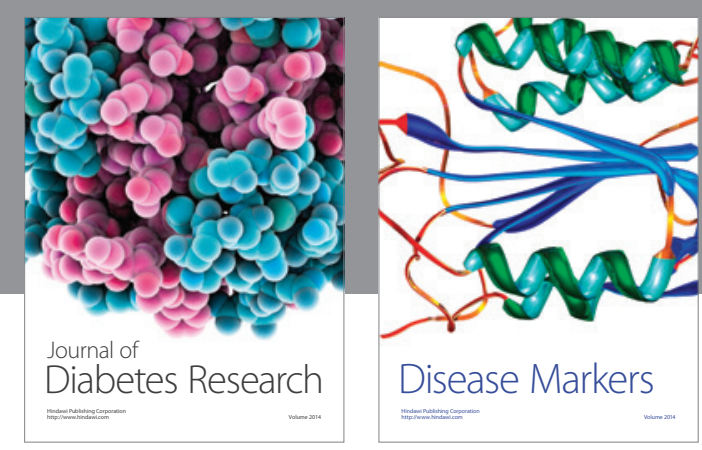

Disease Markers
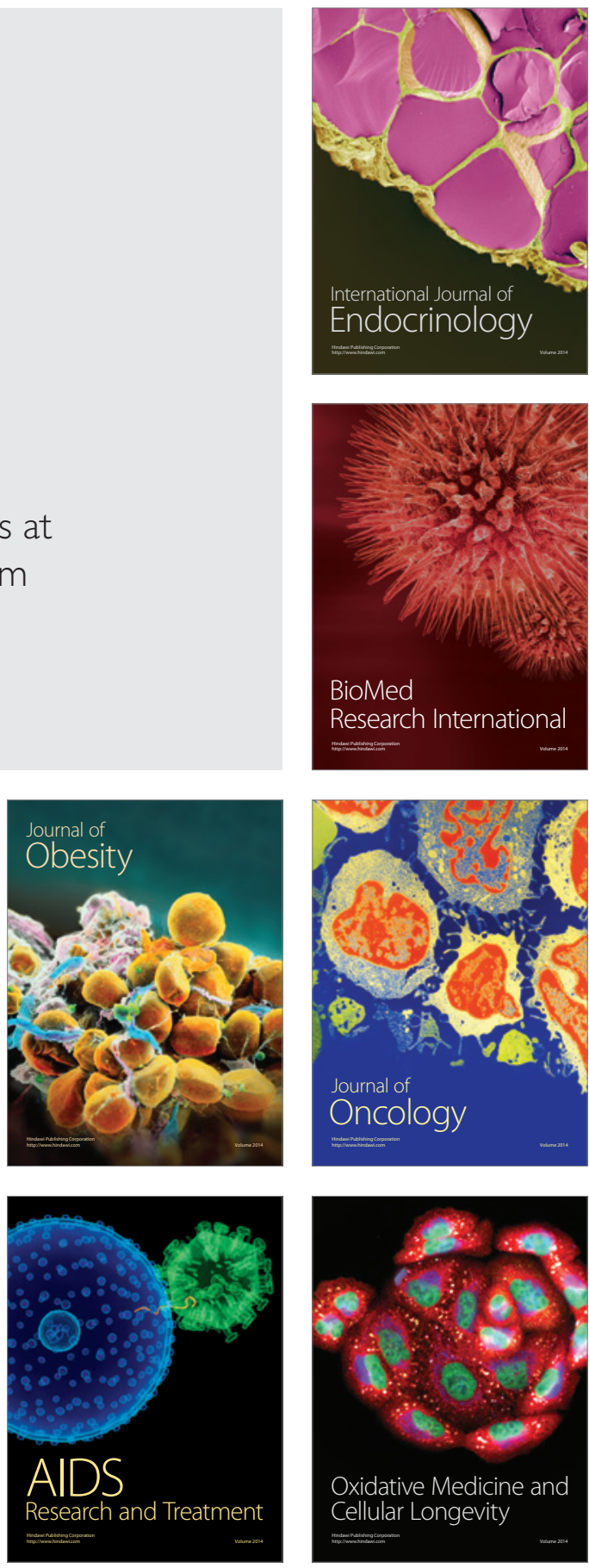